\title{
Ensino e aprendizado sobre dignidade e Direitos Humanos a partir da pandemia da Covid-19
}

- Teaching and learning about dignity and Human
Rights from the Covid-19 pandemic

Ana Maria Klein ${ }^{1}$

Se podes olhar, vê. Se podes ver, repara.

José Saramago

Resumo: A violação dos Direitos Humanos no Brasil persiste apesar do reconhecimento constitucional da dignidade humana e dos Direitos Humanos. A educação é uma via importante para formar sujeitos de direitos capazes de olhar para esta realidade e atuar na sua transformação. O Brasil conta com planos e diretrizes que orientam o desenvolvimento da Educação em Direitos Humanos em todos os níveis e modalidades educacionais. Este tipo de educação pressupõe caminhos metodológicos capazes de promover a reflexão e a problematização da realidade. A pandemia da Covid-19 que afetou e afeta todo o planeta durante o ano de 2020 nos confronta diariamente com a necessidade de garantir os Direitos Humanos das pessoas em nome da sua dignidade. Este artigo propõe-se a refletir sobre as possibilidades de ensino e aprendizagem a partir da problematização do contexto de pandemia em sala de aula.

Palavras-chave: Educação em Direitos Humanos. Dignidade humana. Pandemia da Covid-19.

1 Professora do Departamento de Educação da UNESP/São Jose do Rio Preto. Docente do Programa de Pós-graduação em Ensino e Processos Formativos UNESP. Foi consultora da UNESCO em Educação em Direitos Humanos. Foi membro da Comissão Relatora que elaborou as Diretrizes Nacionais para EDH. ana.klein@unesp.br 


\begin{abstract}
The violation of Human Rights in Brazil persists despite the constitutional recognition of human dignity and Human Rights. Education is an important way to form persons under law capable of looking at this reality and acting on its transformation. Brazil has plans and guidelines that guide the development of Human Rights Education at all levels and educational modalities. This type of education presupposes methodological paths capable of promoting reflection and problematizing reality. The Covid-19 pandemic that affected and still affects the entire planet during the year 2020 confronts us daily with the need to guarantee the people's human rights on account of their dignity. This chapter aims to reflect on the possibilities of teaching and learning by problematizing the context of the pandemic in the classroom.
\end{abstract}

Keywords: Human Rights Education. Human dignity. Covid Pandemic-19.

\title{
Direitos Humanos no Brasil e a dignidade humana
}

O Informe da Anistia Internacional (2017-18) desenha o cenário dos Direitos Humanos no mundo, apresentando a situação de diversos países. Segundo o documento, no Brasil, a violência e os homicídios aumentaram, afetando principalmente os jovens negros; os defensores dos Direitos Humanos não foram protegidos efetivamente e a polícia respondeu à maioria dos protestos com força excessiva e desnecessária. Além disso, houve retrocessos legais; conflitos por terras e por recursos naturais vitimaram dezenas de pessoas; invasões de garimpeiros e madeireiros ilegais nos territórios dos povos indígenas resultaram em vários episódios de violência e assassinatos contra estes povos; tortura e condições degradantes nas prisões persistem. A população de lésbicas, gays, bissexuais, transgêneros e intersexos continua sendo discriminada e morta. A intolerância às religiões de matriz africana concretiza-se por meio de ataques cometidos por fanáticos, por gangues criminosas e por integrantes de outras religiões. As unidades do sistema socioeducativo são superlotadas e os internos submetidos a condições desumanas e degradantes com relatos de práticas de tortura (ANISTIA INTERNACIONAL, 2018, p. 88-89).

E assim, na maioria das vezes que nos referimos aos Direitos Humanos no Brasil, temos este triste e revoltante cenário de violações que ferem a dignidade humana, princípio central dos direitos humanos.

O conceito de dignidade humana passa a ser adotado desde o final do século XI significando honraria. Mas, foi a partir do século XVIII e, sobretudo 
após a Segunda Guerra Mundial, que a dignidade da pessoa passa a referir-se a uma condição que é essencialmente própria à pessoa humana. A dignidade humana reconhece a posição eminente do ser humano em relação às outras espécies, enquanto ser dotado de razão e de sentimentos; trata-se de um atributo que independe de merecimento pessoal ou social, pois ela é inerente à vida e, portanto, é um direito pré-estatal (ANTUNES ROCHA, 2001, p. 52-53).

Os horrores praticados na Segunda Guerra Mundial, destituindo seres humanos de sua humanidade, levaram à Declaração Universal dos Direitos Humanos, DUDH, (ONU, 1948) que se fundamenta no princípio da dignidade humana. Até então, os direitos eram garantidos em função de uma cidadania excludente, de bens materiais e de outros marcadores sociais externos aos indivíduos, protegendo uma classe especifica de seres humanos. O holocausto atingiu homens brancos, com bens e status social da mesma maneira que atingiu minorias historicamente discriminadas. Marcadores externos não foram suficientes para preservar os direitos de segmentos que, até então, tinham sido preservados dos genocídios praticados contra a humanidade, portanto, ninguém estava livre de discursos de ódio e de preconceitos. Daí decorre a ação articulada de diversas nações para adotar um elemento comum e intrínseco a todos os seres humanos sem distinção de sexo, etnia, status social, poder econômico, religião ou qualquer outro atributo que diferencia os humanos. Tornou-se imprescindível que a DUDH afirmasse a integridade e a inviolabilidade dos seres humanos, transcendo marcadores externos. A dignidade humana representa este atributo inerente a todo o ser humano independente das características que nos diferenciam; isto significa que todos nós temos dignidade e esta, por sua vez, se constitui em um valor supremo.

A dignidade humana é reconhecida constitucionalmente pelo Brasil a partir da Constituição Federal de 1988 (BRASIL, 1988) que em seu artigo $1^{\circ}$ afirma que a República Federativa do Brasil tem como um de seus fundamentos a dignidade humana. Na interpretação de Antunes Rocha (2001, p. 53), trata-se do fundamento da própria organização política do Estado Democrático de Direito, significando que o Estado existe para assegurar condições políticas, sociais, econômicas e jurídicas tendo como finalidade o ser humano, como sujeito de dignidade que está acima de todos os bens e coisas, inclusive do próprio Estado.

Apesar do reconhecimento constitucional da dignidade humana e dos Direitos Humanos, persiste no Brasil o perverso cenário de violações de direitos vivenciado diariamente pela população brasileira e constatado, registrado e denunciado em relatórios de organismos nacionais e internacionais, como a Anistia Internacional. 


\section{A educação como via potencial de transformação social}

Obviamente que são necessárias transformações estruturais capazes de enfrentar as desigualdades que estão na base da violação e da negação de direitos no Brasil. A dignidade humana, como princípio da organização estatal implica na adoção de políticas públicas inclusivas capazes de corrigir distorções históricas que aprofundam as desigualdades e resultam em relações injustas e opressoras. Dentre os setores aos quais o Estado deve se dedicar está a educação, que se destaca como uma via imprescindível e necessária para o desenvolvimento das potencialidades humanas e como condição para a realização de outros direitos, uma vez que a educação é ao mesmo tempo um direito e um caminho para a defesa, promoção e reivindicação de direitos econômicos, sociais e culturais.

O Estado brasileiro, desde 2006, por meio do Plano Nacional de Educação em Direitos Humanos, PNEDH (BRASIL, 2018), assumiu o compromisso em desenvolver a Educação em Direitos Humanos (EDH) como uma política pública. Em 2012, o Conselho Nacional de Educação promulgou Diretrizes Nacionais para Educação em Direitos Humanos (BRASIL, 2012), tornando este tipo de educação obrigatória em todas as etapas e modalidades educacionais do país. São dois grandes passos na direção da implementação de uma educação comprometida com os Direitos Humanos, uma vez que as dimensões, princípios, metodologias e bases pedagógicas da EDH estão expressas nestes documentos que servem como referência para redes de ensino, escola e professores.

A EDH é definida pelo PNEDH (BRASIL, 2018, p. 11) como um processo sistemático e multidimensional que orienta a formação do sujeito de direitos, articulando cinco dimensões: conhecimentos sobre $\mathrm{DH}$; valores éticos; consciência cidadã; processos metodológicos participativos e práticas individuais e sociais em favor da promoção, da proteção e da defesa dos Direitos Humanos, bem como da reparação das violações. Para além de conteúdos formais, almeja-se uma formação integral capaz de sensibilizar as pessoas para que olhem para os seres humanos e para o mundo com novas lentes. Trata-se de orientar a vida pessoal, institucional e política por meio de valores éticos compatíveis com os Direitos Humanos.

A EDH conforme proposta pelo PNEDH e ratificada pelas Diretrizes é comprometida com a emancipação das pessoas e com a formação de sujeitos de direitos, tendo por horizonte uma dimensão transformadora da sociedade, com cidadãos capazes de enxergar no outro alguém tão humano quanto si próprio.

A resolução que regulamenta as DNEDH (BRASIL 2012, p. 5) em seu 
artigo $5^{\circ}$ define os objetivos da EDH.

A Educação em Direitos Humanos tem como objetivo central a formação para a vida e para a convivência, no exercício cotidiano dos Direitos Humanos como forma de vida e de organização social, política, econômica e cultural nos níveis regionais, nacionais e planetário.

A formação desejada pressupõe a organização de atividades pedagógicas de modo a viabilizar a reflexão, a possibilidade de debater e compreender diferentes visões de mundo e o reconhecimento do direito do outro (com todas as suas diferenças). Neste sentido, há que se buscar maneiras de organização dos conteúdos e metodologias que favoreçam a participação ativa e reflexiva dos/das estudantes na problematização dos $\mathrm{DH}$.

O ensino e aprendizagem da EDH em suas dimensões (conhecimentos, valores e práticas) demanda metodologias específicas que implicam na compreensão e interpretação da realidade, conjugando a experiência dos indivíduos às ações coletivas. Para tanto, são necessárias atividades pedagógicas que desenvolvam nos alunos capacidades cognitivas (compreender os conteúdos e os conceitos relacionados aos temas trabalhados) e capacidades afetivas e subjetivas (valorar e atribuir significado).

O ensino e a aprendizagem a partir da problematização de contextos reais envolvendo os Direitos Humanos traz sentido aos conhecimentos relativos à conquista sócio-histórica-politica destes direitos. Os estudantes aprendem ao serem confrontados com dilemas éticos, uma vez que problematizam a realidade e ao fazer isso desnudam situações de violações de direitos, talvez invisíveis até então. Torna-se possível enxergar e problematizar preconceitos, discriminações, desigualdades, injustiças, enfim formas de desrespeito à dignidade humana. Com isso, espera-se que os estudantes construam uma visão de mundo crítica e cidadã e sejam capazes de compreender a realidade e, desejavelmente, atuar no sentido de transformá-la.

\section{A pandemia que paralisou o planeta}

O ano de 2020 iniciou com a declaração da Organização Mundial da Saúde (OMS) de que o surto da doença causada pelo novo coronavírus (COVID-19) constituía uma emergência de saúde pública de importância internacional. Em março de 2020 esta mesma organização classificou o surto como pandemia (OPAS/Brasil, julho 2020, s/p).

Pandemia refere-se à doença infecciosa e contagiosa que se espalha muito rapidamente e acaba por atingir uma região inteira, um país, continente etc. Etimologicamente a palavra tem origem no grego (pandemias) e signi- 
fica todo o povo. (DIClO, s/p).

O alto poder de contágio do vírus torna-o transmissível por meio do ar, de superfícies e do contato com pessoas contaminadas. Em poucos dias, grande parte dos países decretaram medidas mais ou menos rigorosas envolvendo isolamento social. Na prática, isso se traduziu na manutenção de atividades consideradas essenciais socialmente e na proibição das demais atividades. De um dia para o outro milhões de pessoas no planeta passaram a ficar confinadas em suas residências e uma solidariedade compulsória fez-se necessária, pois não basta eu ficar confinado se o outro também não estiver, uma vez que a única maneira eficaz de combate ao vírus é não ter contato com pessoas contaminadas que podem não apresentar sintomas e nem saber que são potenciais transmissores do vírus. Desta maneira, a saúde de um depende da saúde do outro.

Em grande parte dos países e mais especificamente no Brasil, as desigualdades sociais intensificaram-se e pelo poder da mídia jornalística e das redes sociais tornaram-se dolorosa e vergonhosamente visíveis. Tornou-se impossível ignorar a realidade que o isolamento social desnudou.

Isolamento social significa para uma grande maioria de pessoas perder sua fonte de rendimentos por não poderem exercer suas atividades laborais e/ou perderem seus empregos. Significa que famílias numerosas que habitam residências precárias com poucos cômodos e sem saneamento básico tiveram que se aglomerar em espaços exíguos com condições limitadas para cumprir os protocolos de higiene requeridos pelo enfrentamento ao vírus. Significa que as pessoas mais pobres que tiveram que manter atividades laborais e dependem de transporte público expõem-se diariamente ao risco de contrair o vírus. Significa que escolas foram fechadas e milhões de estudantes perderam as refeições diárias ali servidas; além disso, a suspensão de aulas presenciais e o desenvolvimento da educação por meio de tecnologias a distancia têm aumentado a desigualdade educacional entre redes públicas e privadas de ensino. Com isso, milhões de estudantes sem acesso à internet e sem computadores em casa estão tendo violado seu direito à educação. No caso de estudantes no último ano do ensino médio trata-se de uma perda irreparável, posto que muitos destes alunos finalizam sua vida estudantil neste nível de ensino e muito provavelmente não terão tido contato com os conteúdos mínimos estabelecidos pelo currículo. O mais grave é que o acesso a conhecimentos científicos dá-se primordialmente por meio da escola e privar jovens destes conhecimentos é deixa-los numa situação de ignorância e desprovidos do pensamento critico, próprio da ciência. Assim, são presas fáceis de discursos de senso comum e fundamentalistas que atendem a interesses escusos e fascistas. Significa que a imensa desigualdade social do Brasil fere 
a dignidade humana de milhões de brasileiros e raramente isso comove as camadas sociais mais ricas da população.

Com o vírus tornou-se impossível ignorar este quadro de violações de direitos, pois o controle da epidemia depende da saúde de cada um. Na nossa sociedade individualista e meritocrática, a vida do outro não me diz respeito, não faz parte do meu conjunto de valores e preocupações. Com o vírus a minha vida passa a depender do cuidado com a vida do outro, não adianta eu me cuidar se milhares de pessoas nas ruas não podem se cuidar e tornam-se potenciais transmissores do vírus. Eu e o outro, desta vez, estamos no mesmo barco. A sociedade foi obrigada a enxergar a pobreza, as habitações precárias, a falta de acesso à agua potável, a falta de moradia, a insegurança alimentar de milhões de famílias, a exclusão digital, as desigualdades educacionais, dentre outras violações à dignidade humana.

Mais do que enxergar esta realidade, a solidariedade compulsória fez com que a sociedade demandasse ações capazes de acolher as necessidades das populações excluídas de seus direitos. E quem seria o responsável por garantir condições dignas de vida às populações pobres? A ideologia neoliberal do "cada um que se vire" tornou-se incompatível com a necessidade de garantir a saúde de todos. O Estado passou a ser cobrado pela sociedade para que empreendesse ações que garantissem renda mínima às famílias, acesso ao sistema público de saúde, politicas educacionais inclusivas. O Estado!

Em um artigo publicado em 2001, Cármen Lúcia Antunes Rocha (2001) reflete sobre a dignidade humana e o papel do Estado, cada vez mais demonizado pelas ideias neoliberais.

[...] Os direitos conquistados, especialmente aqueles que representam um avanço da humanidade no sentido do aperfeiçoamento da sociedade e que se revelam nos direitos sociais, não podem ser desprezados ou desconhecidos, devendo, antes, ser encarecidos e podendo ser ampliados.

O que se apregoa com a globalização neoliberal é o oposto deste princípio: é o retrocesso aos parâmetros do século XVIII, quando o homem tinha apenas alguns parcos direitos individuais, formalmente postos e garantidos sem qualquer força ou eficácia, sem que se obrigasse, ainda, o Estado a prover a sociedade de condições econômicas e políticas sujeitas aos interesses de todos, e não apenas de minorias.

A globalização neoliberal quer o não-Estado ou, pelo menos, o Estado do não-direito, no qual governantes cumprem ordens do comando econômico internacional, o qual, à sua vez, é supraestatal e tem como única finalidade o lucro, obtido a qualquer preço, mesmo que seja o preço do homem. (p. 59-60).

O vírus obrigou a sociedade a ressignificar o papel do mercado e do Estado em relação à promoção dos direitos sociais. Como aponta Boaventura 
de Souza Santos em entrevista ao site BBC News (PICHEL, 2020, s/p)

Nos últimos 40 anos, temos ouvido que o Estado é ineficiente, é corrupto e que o bom são os mercados, que o mercado é o melhor regulador da vida social. Mas aí vem a pandemia e ninguém pergunta pelos mercados. Ninguém pede ao mercado que nos salve, que nos proteja, mas sim ao Estado. Essa é uma lição muito poderosa, e se realmente vamos aprendê-la, temos que reinvestir em educação, saúde, transporte e infraestrutura que não temos.

\section{A problematização nas salas de aula}

A problematização da realidade é fundamental à EDH, pois os Direitos Humanos não são abstrações ou apenas um conjunto de normas, eles tratam de direitos que deveriam fazer parte da vida cotidiana de todos. Assim, olhar para o mundo com a lente dos direitos humanos possibilita perceber sua violação, reconhecer iniciativas voltadas à sua promoção e desenvolver ações criativas, capazes de transformar a realidade.

A realidade desnudada pela pandemia traz importantes aspectos a serem discutidos à luz dos $\mathrm{DH}$ : dignidade humana, direitos sociais, educação e saúde como direitos de todos, acesso à agua, saneamento básico, renda mínima, segurança alimentar, papel do Estado na promoção de direitos, solidariedade social, dentre outros.

Uma sociedade pautada pelos DH implica necessariamente no reconhecimento do direito e da humanidade do "outro" com todas as suas especificidades, diferenças, modos de viver, pensar, existir. Todos merecem o mesmo respeito, o que significa compreender que um grupo não pode oprimir o outro em razão de qualquer diferença seja biológica, cultural, religiosa ou ideológica. Mas este não é um reconhecimento meramente formal ou legal, implica em sentimentos e neste sentido, a dor causada pelo vírus aproxima a todos, expõe a nossa humanidade, pois ninguém está imune à doença. Cuidar de si próprio passou a significar cuidar do outro também. Na análise de Boaventura de Sousa Santos, o vírus é um professor. "O vírus é um professor no sentido de que ele está nos dando várias lições. O problema é saber se nós vamos escutar e aprender. $O$ cruel é que a única maneira que o vírus tem de nos ensinar é matando, matando inocentes, milhares e milhares deles" (PICHEL, 2020, s/p).

Trabalhar com a EDH traz vários desafios, dentre eles a necessidade de "tocar" os alunos, ir além de uma educação conteudista e provocar a reflexão e o despertar do sentimento de humanidade. Lembro-me da minha querida professora e inspiradora Maria Victoria Benevides (2003, p. 309) dizendo que temos que atingir mentes e corações promovendo o respeito à dignidade humana. 
É a formação de uma cultura de respeito à dignidade humana através da promoção e da vivência dos valores da liberdade, da justiça, da igualdade, da solidariedade, da cooperação, da tolerância e da paz. Isso significa criar, influenciar, compartilhar e consolidar mentalidades, costumes, atitudes, hábitos e comportamentos que decorrem, todos, daqueles valores essenciais citados - os quais devem se transformar em práticas.

\section{Considerações finais}

Professoras e professores podem contribuir para que a pandemia seja vista para além das mortes que ocasionou, para que os seres humanos vitimados ou não e suas condições de vida sejam vistos e considerados como sujeitos de direitos tendo como principio a dignidade inerente a todas as pessoas.

... E fica a esperança que esse cenário possa ser visto (por mentes e corações) para ser reparado.

\section{Referências}

ANTUNES ROCHA, Carmem Lúcia. O princípio da dignidade da pessoa humana e a exclusão sociaL. Revista do Instituto Brasileiro de Direitos Humanos, Fortaleza, [S. I.], n. 2, p. 49-67, dez. 2001. Disponível em: http://revista.ibdh. org.br/index.php/ibdh/article/view/29. Acesso em: 7 jul. 2020.

ANISTIA INTERNACIONAL. Informe 2017/18: O estado dos direitos humanos no Mundo. Reino Unido, 2018. Disponível em: https://anistia.org.br/entre-em-acao/carta/informe-anual-20172018-o-estado-dos-direitos-humanos-mundo/. Acesso em: 7 jul. 2020.

BENEVIDES, Maria Victoria. Educação em direitos humanos: de que se trata. In: LEITE, Raquel Lazzari (org.). Formação de educadores: desafios e perspectivas. São Paulo: Editora UNESP, 2003. p. 309-318.

BRASIL. Constituição da República Federativa do Brasil (1988). Brasília, DF: Senado Federal: Centro Gráfico, 1988.

BRASIL. Comitê Nacional de Educação em Direitos Humanos. Plano Nacional de Educação em Direitos Humanos. Brasília: Ministério dos Direitos Humanos 2018.

BRASIL. Ministério da Educação. Diretrizes Curriculares Nacionais para a 
Educação em Direitos Humanos. Resolução CNE/CP 1/2012. Diário Oficial da União: seção 1, Brasília, DF, 31 maio 2012.

DICIO. Dicionario on line de português. Disponível em: https://www.dicio.com. br/pandemia/. Acesso em: 23 jul. 2020.

ONU. Declaração Universal dos Direitos Humanos. França,1948. Disponível em: https://nacoesunidas.org/direitoshumanos/declaracao/ Acesso em: 26 jul. 2020.

PICHEL, Mar. O coronavírus é um professor cruel porque ensina matando. BBC News, 4 de julho de 2020. Disponível em: https://www.bbc.com/portuguese/geral-53281462. Acesso em: 6 jul. 2020. 